Faculty of Education

Te Kura Toi Tangata

Waikato Journal of Education

Te Hautaka Mātauranga o Waikato

Volume 16, Issue 2: 2011 


\section{WAIKATO JOURNAL OF EDUCATION TE HAUTAKA MĀTAURANGA O WAIKATO}

\section{Editors:}

Jane Strachan

Noeline Wright

\author{
Editorial Board: \\ Beverley Bell \\ Bronwen Cowie \\ Deborah Fraser \\ Margie Hohepa \\ Sally Peters \\ Noeline Wright
}

\author{
Margaret Carr \\ Rosemary DeLuca \\ Richard Hill \\ Judy Moreland \\ Clive Pope
}

Waikato Journal of Education is a refereed journal, published annually, based in the Faculty of Education, The University of Waikato, Hamilton, New Zealand. It publishes articles in the broad field of education. For further information visit the WJE website http://edlinked.soe.waikato.ac.nz/research/journal/index.php?id=8

Correspondence and articles for review should be addressed to: Research Manager, Wilf Malcolm Institute of Educational Research, Faculty of Education, The University of Waikato, Private Bag 3105, Hamilton, 3240, New Zealand. Email: wmier@waikato.ac.nz

Business correspondence: Orders, subscription payments and other enquiries should be sent to the Administrator, Waikato Journal of Education, Wilf Malcolm Institute of Educational Research, Faculty of Education, The University of Waikato, Private Bag 3105, Hamilton, 3240, New Zealand, Email: wmier@waikato.ac.nz

Subscriptions: Within NZ \$40; Overseas NZ \$50

Copyright: (C) Faculty of Education, The University of Waikato

Publisher: $\quad$ Faculty of Education, The University of Waikato

Cover design: Donn Ratana

Printed by: Waikato Print

\section{Call for papers}

The Waikato Journal of Education provides an avenue of publication for quality articles on education. This peer-reviewed journal welcomes a range of topics including interdisciplinary, philosophical and applied research approaches.

Submissions are now invited for consideration for publication in the November 2012 issue. Please submit an electronic copy and a separate page with author/s contact details by 30 April 2012 to WMIER Research Manager, Carolyn Jones (cjjones@waikato.ac.nz), Faculty of Education, University of Waikato, Private Bag 3105, Hamilton 3240, New Zealand. 


\section{Waikato Journal of Education}

\section{Te Hautaka Mātauranga o Waikato}

Volume 16, Issue 2: 2011

\section{Special Edition: A teacher education partnership between the Solomon Islands and New Zealand}

Editorial

The Solomon Islands School of Education Partnership: Aspirations, context and design in educational change

Clive McGee and Patricia Rodie

Partnership experiences in developing the Preparation for Tertiary Learning course in the Teachers in Training programme

Roselyn Maneipuri, Immaculate Runialo and Noeline Wright

Making sense of health education in the Solomon Islands

Kirsten Petrie and Mark Tehe

The Solomon Islands mathematics: Pedagogy in transition?

Nigel Calder, John Beuka and Calvin Ngatulu

Taking ownership: The story of a successful partnership for change in a Pacific Island science teacher education setting

Richard Edwards, Solomon Pita and James Porakari

Funds of knowledge: Developing a Diploma in Teaching in Early Childhood Education in the Solomon Islands

Janette Kelly, Joanna Daiwo and Viola Malasa

Weaving a "Hybrid Mat": Samoa meets the Solomons

Barbara Whyte

Sustaining organisational change: Teacher education in the Solomon Islands Jane Strachan, Susanne Maezama and Janine Simi

Exploring factors that influence school planning in community high schools in the Solomon Islands: Principals' perspectives

Samuel Aruhu and David Giles

Experiences of being a leader in Choiseul Province: Opening principals' and deputy principals' contexts of leadership

John Sisiolo and David Giles

Book review 
Waikato Journal of Education

Te Hautaka Mātauranga o Waikato

Volume 16 Issue 2: 2011

\title{
The Solomon Islands School of Education Partnership: Aspirations, context and design in educational change
}

\author{
Clive McGee \\ University of Waikato \\ Patricia Rodie \\ Solomon Islands College of Higher Education
}

\begin{abstract}
This article provides a background and context for a project that linked the School of Education in Solomon Islands College of Higher Education (SOE) with an external partner to work together on institutional and educational change. The four and a half year Partnership was funded by the New Zealand Aid Programme. Pre-service teacher education in Solomon Islands is mainly provided by the School of Education. For a number of years the school has faced many challenges in its attempt to offer quality pre-service teacher education. Some challenges were external, such as political instability and ethnic unrest, and some were internal, such as a need to address the school's aims, design of programmes, quality of teaching, learning and assessment and the professional development of academic staff. We explain how the partnership responded to challenges and evolved in a way that recognised the input of the School of Education staff and avoided the imposition of solutions by the external partner. The major aspirations and intentions of the Partnership are described along with indications of positive changes that led to an extension of the project. A major change in the school was the inclusion of a teacher education programme for some of the many untrained practising teachers in the Solomon Islands. It is pointed out, however, that there were risks and challenges that faced the Partnership over its duration. Some were outside the control of the partners and others could be addressed and improvements made, especially within the school using a collaborative approach. It is argued that issues remain and further impetus is needed to effect more lasting change.
\end{abstract}

Faculty of Education, University of Waikato, Hamilton, New Zealand

ISSN: 1173-6135

(pp. 7-19) 


\section{Keywords}

Educational change, teacher education, change partnerships, capacity building, partnership risks.

\section{Background to the project}

History

The Solomon Islands is a small sovereign state near Papua New Guinea, made up of nearly 1,000 islands scattered over a large territory and adding up to just over 28,000 square kilometres. It is a constitutional monarchy with a parliamentary system and is part of the Commonwealth of Nations (British Commonwealth), having gained independence in July 1978. The population is over 500,000 (2009 estimate: Wikipedia), occupying about 350 of the islands. Melanesians make up most of this number. Most people live in villages and the capital, Honiara, is the only large urban centre with about 60,000 people. There are high birth rates resulting in a growing demand for places in schools and qualified teachers.

Although English is the official language, only a few people who engage in formal employment speak it. Most speak the everyday Solomons Pijin and various local Melanesian languages. Christian missionary influence on the indigenous population was strong and today nearly all people are Christian and belong to a range of churches - the three largest denominations being the Anglican Church of Melanesia (about one-third of the population), Roman Catholic (one-fifth) and just under one-fifth belong to the South Seas Evangelical Church. Economically, the Solomon Islands is one of the poorest countries in the Pacific region; many are employed in subsistence activities, unemployment is high and the economy depends heavily upon international aid.

Even from this elementary information it is not hard to imagine that the Solomon Islands government struggles to finance teacher education and schools without international aid. There are many untrained teachers and one of the goals of the government is to train them as well as new teachers. Formal institutional teacher education in the Solomon Islands is comparatively recent. This paper focuses upon the School of Education in the Solomon Islands College of Higher Education (SICHE), an institution established in 1984. First called the School of Education and Cultural Studies - one of four schools in the SICHE - the school grew out of the Teachers' and Vocational Training College (1955) that later became the British Solomon Training College and later still the Solomon Islands Teachers' College and in 1984 a new school in SICHE. The name of the school was changed in the mid-1990s when "and Cultural Studies" was removed because the main activity was teacher education. The first teacher education credential offered at the original teacher education institution was a two-year Certificate in Teaching for primary teaching. The certificate was extended to three years in residence in the 1970s, but soon changed to two years in residence and one year of supervised teaching in schools. A Certificate for Provincial Secondary Schools began in the 1970s and was replaced in 1981 by a Diploma in Teaching (Secondary) programme in 1981, run in conjunction with the University of the South Pacific. 
The Solomon Islands offered its own teaching credentials at the SICHE: certificates for early childhood and primary supported by a one-year foundation programme for school leavers. Revised diplomas for secondary teaching were introduced in 1988. There were few reviews of credentials in the 1990s, although an external review by Dunedin College of Education assisted with the review and revision of the primary Certificate in Teaching.

The School of Education is the major supplier of credentialed teachers in the Solomon Islands. Over the last couple of decades, donor project finance has provided much of the infrastructure in the SICHE and the SOE, including accommodation and teaching buildings, library and teaching resources. In 2004 there were over 600 student teachers, about 300 in a primary teaching certificate, about 300 doing a secondary diploma and a small number in an early childhood certificate.

These recent successes are tempered by the reality of a difficult last 10 years, a period of political and ethnic unrest in the Solomon Islands with negative impacts upon the SICHE and the SOE and the wider economy and social structure. In the early 2000s teaching in the SOE stopped and the infrastructure was seriously damaged. During a more stable time in 2004, the Ministry of Education and Human Resource Development (MEHRD) set up a review of the SOE (Taylor \& Pollard, 2004) to look at "issues and barriers to the provision of quality teacher education ... the school can work to overcome these" (p. 12) and teacher supply and demand. The external reviewers recommended a three-year development plan for the SOE to build capability and capacity, a plan that would need external aid.

A brief summary of the review findings provides contextual information about the SOE that helps explain the need for the Partnership project described in this article. In terms of capability in the SOE the reviewers found consistency in the views of the major teacher education stakeholders. It was generally agreed that the SOE was somewhat isolated as a provider of teacher education. For some years preceding the review there had been little contact between key teacher education stakeholders such as the education ministry, the Curriculum Development Division, Principals' Association, and the Solomon Islands National Teachers Association. There were missed opportunities for contacts that would have strengthened teacher education by being closely connected to schools, government policy makers and curriculum developers.

School teachers and principals reported that the graduates of the SOE were generally well regarded as teachers with good teaching skills although not necessarily up to date with school curriculum. Some saw a lack of collaboration between the SOE staff and Curriculum Development Division staff as a contributor to this curriculum issue. Another concern was a low level of professional behaviour among a minority of graduates and even teacher educators, especially men, who were thus failing as role models and effective practitioners.

There were a number of institutional factors in the SOE and SICHE that affected the quality of teacher education. The reviewers saw evidence of inadequate facilities and resources such as uneven levels of academic staffing and workloads across departments and individuals, a cumbersome timetable with unhelpful clashes, and too few and poorly resourced teaching spaces. To the reviewers, all of these problems could be solved with effective management and leadership of revised policies provided necessary resources could be found. The teacher education programmes had not been reviewed for a number of years, resulting in a neglect of international scholarship on emerging 
knowledge and developments in best practice in programme design and teaching. It was reported that the central task of teaching student teachers was not being carried out as well as it could have been. There was a need to review and develop all aspects of effective teaching from the phase of planning and preparation to classroom implementation and assessment of learning. Associated wider concerns were the need to design quality course outlines within programmes and assessment policies.

In terms of capacity the reviewers noted that there was a serious shortage of qualified teachers in the Solomon Islands yet the SOE did not have the capacity to take more students. This issue is tied up with the wider national context. If the SOE was to be expanded to take more students, more resources would be needed. It appeared that the Solomon Islands government could only expand the SOE with international project funding. The reviewers recommended that a range of options to increase capacity should be considered, including teaching untrained teachers in flexible ways such as more recognition of teaching experience and a mixture of on-campus and local area teacher education.

To meet the challenge of issues of capability and capacity in the SOE, the review report suggested the setting up of a three-year contract to partner the SOE with an external institution to identify needs and develop and carry out a plan of implementation. The recommendation was acted upon reasonably quickly by the Solomon Islands College of Higher Education, the Solomon Islands government and the New Zealand Aid Programme. A contract was let in early 2006 for a three year twinning arrangement between the SOE and an external partner, the Faculty of Education at the University of Waikato in association with the International Training, Research and Education Consortium (InTREC), a United Kingdom consortium of several universities. Globally, it has been recognised in recent years that a key to successful change through international aid programmes is the formulation of partnerships between external providers and the recipient country. To succeed, a partnership needs the full participation of both partners in decision-making about policies and practices. Both partners need to "own" the changes, according to an international declaration on change (OECD, 2005). This principle was reaffirmed in the Pacific context by the Pacific Islands Forum Secretariat (2007). It was argued that what must be avoided is the imposition of external change upon a passive recipient country.

In the meantime, in early 2006 - while the Partnership was being negotiated - an internal review of all programmes in all the SICHE schools was initiated through a oneweek workshop that included a range of stakeholders. The School of Education review covered an appraisal of the current teacher education programmes - their structure and design, delivery, teaching practices, academic requirements and regulations, assessment, content and staffing. The review also considered the upgrading of early childhood and primary certificates to diplomas. The proposals provided a basis for work that would follow during the Partnership or twinning arrangement, which began in the second half of 2006 and is outlined below. Importantly, the workshop provided a number of the SOE academic staff with the experience of looking closely at the existing credentials and increasing their awareness of issues in the design, delivery and assessment of programmes and courses and the political, logistical and financial issues involved. 


\section{Partnership model}

The first section of this paper provided the context of teacher education in the Solomon Islands. This second section outlines a Partnership proposal that was agreed between the New Zealand Aid Programme, the School of Education (SOE) at the SICHE, and the University of Waikato (UOW). It describes the aims, aspirations and philosophical underpinnings, scope, timeline, activities and tasks, risks and quality assurance. It outlines some of the main partnership activities and identifies issues and challenges facing the partnership: political, financial, institutional, intercultural and philosophical.

\section{Context}

The Partnership was called Solomon Islands-School of Education Support Partnership and was funded by the New Zealand Aid Programme. The University of Waikato, in collaboration with several UK universities, was chosen as the external partner following a contestable tendering process. The university designed a joint proposal with a consortium of six leading UK universities called the International Training, Research and Education Consortium (InTREC) ${ }^{\mathrm{ii}}$. The overall management and administration of the project was located at the University of Waikato. Together, the University of Waikato and InTREC were known as the external partner. The external partner represented a large base of experience and expertise in contemporary teacher education and international education. The project began in mid-2006 and was scheduled to end in mid-2009. However, due to review evidence (Wrightson, 2008) and from successful SOE leadership of changes in the SOE, the New Zealand Aid Programme decided to extend the project to the end of 2010 to capitalise on the success that will be referred to in this paper.

The external partner personnel were aware of factors in the Solomon Islands that would impact upon the project. First, when the Partnership began the Solomon Islands had recently experienced a period of intense conflict that had impacted on the economic, social and political lives of its citizens. The education services, including those at the Solomon Islands College of Higher Education, had been badly affected, including the morale and confidence of the staff. Post conflict, and with the assistance of international aid, both multilateral and bilateral, the Solomon Islands was in a phase of rebuilding. A critical aim of that rebuilding was restoring the morale and confidence of the people, a critical consideration for this Partnership. Building mutually respectful relationships between the external partner staff and staff of the School of Education was seen as essential to the success of the contract.

Second, there were cultural aspects, which included the strongly held Christian beliefs of most Solomon Islanders, and gender issues that needed to be considered. There were also limited educational resources and there was a need to work within those limitations. It was also seen as important that the external providers act as professional advisers and mentors to the SOE staff and provide support to prioritise, plan and implement changes. Therefore, the methodology for this contract was to be a Partnership model of professional development (Robertson, 2005) and would involve three phases that were not discrete but would overlap in both process and content.

Third, external partner leaders were aware of the historical pitfalls of international donors working in Pacific nations, in particular a tendency for the donor to impose 
solutions and strategies. Baumgart (1994) long ago advocated the need for powersharing partnerships and identified a number of key policy areas that should be considered, including social justice and the nature of curriculum and its delivery. This was the basis of a fundamental principle of this partnership, namely, to develop a Partnership based upon cooperative action and decision-making. More recently the need for this principle has been reinforced by Coxon and Munce (2008), who have argued that aid donors to Pacific countries have tended to stifle the indigenous contribution to structures and procedures in trying to create culturally appropriate education.

Structures and procedures may not go far enough. Another dimension of indigenous involvement is the need to probe more deeply into indigenous thought processes such as theory formulation, concepts of learning and knowledge. Huffer and Qalo (2004) argued that in any partnership, greater recognition should be given to distinctive modes of Pacific thinking, learning and knowledge and how they can be shown to be relevant for contemporary curriculum development, for example, teacher education curriculum. There was an awareness of this challenging issue in the Partnership.

From the early stage of negotiations over the form and activities, it was recognised by external partner personnel that it was necessary to expect the unexpected during the partnership. For example, political unrest delayed the start of the project, scheduled for mid-2006. In 2007 there was a major earthquake in Solomon Islands followed by a large tsunami. Over 50 people were killed, over 900 homes destroyed, and thousands of people left homeless. There were implications for the Partnership such as some student teachers being unable to complete their programme in the School of Education in time to graduate.

\section{The Partnership}

The design of the Partnership was based upon the analysis of the existing needs in the SOE and the response of the external partner in proposing ways of meeting them. Both the New Zealand Programme and the external partner were of the view that meeting needs should be based upon close collaboration and consultation with the personnel of the SOE. This was one of the major aspirations of the Partnership, that is, the SOE and the external partner would work together to identify and act upon needs to bring about improvements.

Another aspiration was that the SOE would gradually assume ownership of the need to change and the strategies to change. A further aspiration of the Partnership was to identify existing strengths in the School of Education and build upon them. To translate these aspirations into a commitment to change and real change, there was a realisation by School of Education leaders and the external partner that the notion of capacity building was of central importance. Capacity building related to the quality of the educational programmes offered in the School of Education, the teaching and learning methods, including assessment policies and processes, and the teaching and learning facilities. Developing leadership across the school was seen as essential. There was also a need to develop the research capability of the School of Education academic staff. A number of them had good academic qualifications but had produced little research and writing, in part due to heavy teaching loads and in part to a paucity of research leadership. An awareness of these factors influenced the partnership design of the external partner. 
There were three major phases in the partnership design. The first initiation phase of the contract focused upon relationship building and collaboration. It involved identifying needs and prioritising changes. Creating ownership of agreed changes was a critical component of early professional development and was continued through all three phases. This was to occur through

- consultation with SOE staff through all phases to ascertain needs and priorities, plan actions, and ascertain cultural appropriateness;

- the establishment of counterpart relationships between key external partner and SOE leaders;

- the establishment of counterpart relationships between teams and individuals;

- external partner staff learning some Solomon Island's Pidgin. Even though staff of the SOE speak English, it is a mark of respect to be able to converse in the lingua franca;

- the provider institutions freely sharing information with SOE staff;

- negotiation of agreed understandings of the nature and purpose of the partnership model;

- consultation with other key stakeholders such as the Ministry of Education and Human Resource Development (MEHRD), students and schools; and

- a process of seeking advice from local counterparts with regard to the cultural appropriateness of suggested strategies and initiatives. While the providers were professional experts in their field they did not regard themselves as cultural experts.

The second phase was to be implementation. It would focus upon the capacity building of SOE staff that was seen as a key aspect of the success of the project. At the end of the contract, when staff of the provider institutions withdrew, it was intended that SOE staff would have the capacity, confidence and skills to be able to institutionalise changes. This was to occur through

- consultation with SOE staff to plan and review actions;

- provision of current information based on best practice and research on initial teacher education;

- teacher educators to continue their own professional development and learning; and

- the establishment of professional partnerships between the academic staff of the external partner institutions and the SOE academic staff to maximise capacity building and transferability of information and skills. Communication would occur during site visits and via email. The professional partnerships would be diverse and based on expertise at the individual level (for example, practicum coordinators), the team level (for example, primary initial teacher educators in different curriculum areas) and the institutional leadership level (for example, strategic planning and policy development).

The third phase of the planned partnership was called institutionalisation. It was focused upon embedding the changes and planning for the future and occurred through providers working with SOE staff to develop a strategic plan, associated polices and action plans. There was to be ongoing partner support via email and training for SOE staff in the management of the change process. A goal was to embed a strategic 
planning process that was clear, rigorous and acceptable and that would continue to be used beyond the end of the project funding. Similarly, it was intended to embed a quality assurance and improvement process that was also clear, rigorous and acceptable and would also be used beyond the Partnership.

The success of institutionalising changes was seen as dependent upon the preceding two phases. In particular, it seemed essential that those responsible for embedding the changes feel confident in their capacity to do so. They needed both skills and knowledge, but most importantly, they needed to own the changes. There was a record of effective professional development practice by staff at the Faculty of Education, University of Waikato and InTREC universities to achieve deep and lasting changes in the practice of educational leaders and managers and academic staff.

The main difference between this Partnership project and previous partnerships in the 1990s was that it placed more emphasis on inclusiveness, teamwork, collaborative practice, and working in partnership as opposed to a selected few receiving expert advice and direction from overseas experts.

Having described some of the aspirations and intentions of the Partnership, we now turn to an examination of some of the factors that impacted upon the realisation of successful implementation.

\section{Risks}

During the implementation phase of the partnership, there were risks that had to be taken into account. The political situation in the Solomon Islands was volatile and the Partnership began against a backdrop of uncertainty about the stability of government. There were geographical, cultural and financial differences between the partners that might have affected the level of mutual understanding of the aims, procedures and outcomes of the Partnership. More specifically, there were differences in teaching approaches and research involvement of academic staff and it was difficult to estimate the degree of change within expected time targets. There were technology issues regarding teaching and communication between partners. For example, access to computers was much more limited in the SOE than in the partner institutions and the computers were susceptible to humidity damage, viral infections and poor Internet access.

There were work pressures on SOE staff to teach large annual on-campus cohorts of teachers in training as well as regular on-campus students, later changed to distance teaching. In the early stages of the Partnership national political instability was an ongoing risk but there was greater stability after about one and a half years. For external providers there were ongoing risks of not being able to meet deadlines of Solomon Islands arrivals and departures due to unreliability of flights. At times there was a short supply of satisfactory accommodation in the capital, Honiara.

\section{Governance and leadership of the partnership}

The project required efficient financial and logistical management. The key stakeholders negotiated methods of planning and delivering the activities of the Partnership. Financial matters were handled by the manager of the Wilf Malcolm Institute of Educational Research, who worked with the contracts division of the University of Waikato and the finance section of the New Zealand Aid Programme to 
agree on the costs of each Partnership phase and the systems of financial tracking and reporting. The aims and activities of the project were overseen by an advisory group of senior university staff, an external consultant and Solomon Islands representatives who were at the University of Waikato doing graduate study, and who had previously held senior positions in the SICHE or the Curriculum Development Division (CDD), and the partnership director. It met several times a year to provide input into work plans for each phase, feedback during implementation phases and feedback on completion. The group provided advice to the director on issues as they arose during the course of the project, which enabled better responses to risks.

The director of the Partnership was an experienced teacher educator with a record of work in educational institutions in the Pacific region. Her views and approach matched the goals of the partnership: that it would be inclusive, consultative and evolve in ways that were relevant and positive for change in the SOE. The director realised the importance of face-to-face communication in processes of educational change in line with established international literature. For example, Fullan (2001) argued that it is necessary in large-scale change for facilitators to understand the local context and to achieve a sense of ownership of change in those who are changing, in this case the staff in the School of Education. In working with SOE staff a goal was to achieve a collaborative relationship with the external partner staff in line with principles of communities of practice that are becoming a powerful force in educational change and practice (Collarbone, 2003). Consequently, the director made regular visits to the SOE to achieve positive relations and maintain a momentum in the partnership by ensuring that agreed activities were being carried out.

Quality assurance was achieved through a formal relationship between the SOE and the external partner. Over the four and a half years of the partnership, there was a regular pattern of agreed work plans, usually covering one year, and quarterly and annual milestone reports on the delivery of each plan. These regular reports and the governance described above contributed to systematic quality assurance, along with ongoing consultation and negotiation between the project director and the School of Education leaders and staff in the SICHE. Annual review meetings were attended by the SOE, the Head of SOE and external partner representatives. An independent review was also used by the New Zealand Aid Programme as a method of quality assurance. A review was carried out in April-May 2008 (Wrightson, 2008), nearly two years after the start of the project. One of the key recommendations was the need to establish the strategic positioning of the SOE as the government's main teacher education provider and that the external partner role should include help for the SOE to plan its strategic direction. Generally, the report noted many positive outcomes related to changes in the operation of the SOE.

\section{Partnership activities}

We have outlined the major intentions and aspirations of the partnership and drawn attention to some of the more general factors that were related to implementation. As it unfolded there were numerous activities in the Partnership. Many of them will be described and discussed in other articles in this issue. Our purpose in this section is to briefly discuss, more generally, some of the factors that impacted upon the Partnership as a whole. 
The first six months of the project in 2006 was a period of establishing relationships and building confidence between the SOE and the partner institutions. Key roles were played by the Head of SOE and the Partnership director. Evidence from reports to the New Zealand Aid Programme and a later independent review showed a positive commitment by both parties to the success of the project. This first phase focused upon several activities. A proposal to revise the two-year diplomas of teaching was formulated and involved the SOE Policy and Planning Committee and Partnership institution personnel. Revised policies for equity, assessment and teaching experiences in schools were formulated. A programme of professional development and learning for SOE academic staff was developed. The SOE science, mathematics, arts and language, education studies and social sciences departments entered into a development process with partner institution staff to revise the approaches to professional development, course development and better ways to align with the Curriculum Development Division. A draft certificate programme for teaching unqualified teachers in the SOE was developed and three new courses designed as the first part of the programme to be delivered in 2007. In subsequent years the whole programme has been designed and taught.

Risks emerged in this early phase. The Head of the SOE left to take up doctoral study, resulting in a new, less experienced Head being appointed. Logistical issues impacted, such as computer viruses and email difficulties. Partner institution staff found that some tasks had not been completed by the SOE staff in time for partner visits to the SOE. These were challenges that were addressed by the project director and the new Head of the SOE.

The next phase of the project in 2007 saw a consolidation of these early developments. A number of partner institution staff visits to the SOE resulted in advances in programme and course design, and leadership strategies in the SOE. The role of the SOE Policy and Planning Committee became more prominent in regular work on credentials and policies for delivery of courses and assessment of courses and school practice. Research-building activities began with seminars by SOE staff on their research activity.

The remainder of the project was based upon further advancements in the activities already mentioned. Evidence from a review conducted by NZAID (Wrightson, 2008) and the regular project reports to NZAID showed many positive outcomes that were substantiated by SOE staff comment and documentary evidence. As a result NZAID decided to extend the project to the end of 2010 rather than lose the opportunities to build on the momentum of changes in the SOE. Consequently, by the end of the project a number of achievements were evident. SOE leaders and staff were clear about the strategic direction of the SOE and its place as the main teacher education provider in the Solomon Islands. Improvements were made in the quality of leadership at various levels in the SOE. There were improved professional relationships between the SOE and other major teacher education stakeholders.

The quality of initial teacher education programmes had improved as evidenced by revised programmes and courses, teaching, assessment and school-based experiences. There were procedures in place for a review of teaching qualifications. All existing programmes had been upgraded to diplomas and certificates designed for unqualified teachers. In 2010 the following numbers graduated: 43 in Diploma of Teaching Early Childhood; 113 with Diploma of Teaching Primary; 127 with Diploma of Teaching 
Secondary and 50 with Graduate Diploma in Secondary; 52 Certificate in Teaching Early Childhood. In 2009 and 2010 nearly 250 untrained teachers also graduated (Strachan \& Simi, 2010). Completion rates in 2010 were very high by international standards in spite of travel problems for some untrained teachers affected by an earthquake, cyclonic weather and a tsunami. At the end of the project there was a proposed design for an undergraduate teaching degree. There was an increase in the research capacity of SOE academic staff, a research monograph featuring SOE staff outputs was published in 2010 and several research seminars were presented.

Another development during the partnership was a diversification of the roles of SOE academic staff. Some became engaged in the provision of in-service education for the professional learning of teachers in various regions. There was the new programme to teach unqualified teachers referred to already. Finally, there is now ongoing involvement in teaching teacher education students at a distance in an attempt to overcome the necessity to always teach courses at the SICHE campus. New policies were developed for several key aspects of teacher education and a new teaching timetable was designed that matched course and programme changes.

\section{So how did we do?}

Self-review occurred throughout the duration of the partnership and informed yearly planning. While this was a very useful process, it was not without its limitations-when you are in the middle of the forest, sometimes it is difficult to see the wood for the trees. It is usual practice that both during and after the completion of a project the New Zealand Aid Programme commissions an independent review. After all, New Zealand taxpayer money was being spent and they wanted to know, amongst other things, if they had got value for money.

Early in 2011, the New Zealand Aid Programme commissioned a comprehensive independent review. Vince Catherwood and Lester Taylor, two very experienced New Zealand educators, were contracted to carry out the review. Their terms of reference were extensive but in brief their objectives were to

- assess the relevance of the partnership;

- assess the effectiveness of the partnership in achieving the six original objectives and the additional objectives. This includes a qualitative and quantitative assessment of the results of the partnership, including impact on SOE and the wider SICHE capacity, graduates, course structure and materials;

- assess the efficiency of the partnership. The analysis focuses on

- value for money;

- efficiency of systems, process, governance and management structures; and

- quality of management, including financial and risk management;

- assess the sustainability of the benefits of the partnership; and

- draw lessons learned from the partnership arrangement for SOE, SICHE, MEHRD, the University of Waikato and Development Partners, and to provide recommendations to assist SOE to identify, prioritise and plan further improvements and support, including recommendations for future support needs.

(Catherwood \& Taylor, 2011, p. 14) 
Overall, Catherwood and Taylor (2011) found that there were some particular strengths of the partnership including

- the completion of a comprehensive review and redevelopment of the SOE's total teacher education curriculum;

- the successful delivery of a programme of professional development for the staff of the SOE; and

- an institutional strengthening programme for the SOE as a whole. (p. 5)

They concluded that we were able to achieve this because of the development of mutually respectful relationships, by creating a sense of ownership of the changes by the SOE staff, by "providing support and expertise" (p. 6), and by giving the SOE staff time to reflect on the changes (Catherwood \& Taylor, 2011).

Although they also concluded that the Partnership had delivered value for money, they warned that sustainability of the changes could not be guaranteed. That would depend upon effective leadership in the SOE.

Their review also highlighted some lessons learned, including that the initial threeyear term was never going to be long enough to be able to achieve the objectives. They also cautioned that there was some overloading of the SOE staff as they grappled with a huge amount of information and work.

Their review both supported findings in our self-reviews provided in the many partnership reports and also has provided us with valuable feedback to inform and improve future similar work.

\section{References}

Baumgart, N. (1994). Primary and secondary education for development: Key decision areas. In OECD (Eds.), Issues in education in Asia and the Pacific: An international perspective; Proceedings of a conference in Hiroshima (pp. 95103). Paris: Author.

Catherwood, V., \& Taylor, L. (2011). Evaluation of the School of Education (Solomon Islands College of Higher Education) and the University of Waikato Partnership (Report commissioned by the New Zealand Aid Programme). Wellington, New Zealand: Vince Catherwood and Associates.

Collarbone, P. (2003). Leading the learning community. In B. Davies \& J. WestBurnham (Eds.), Handbook of educational leadership and management (pp. 375-380). London, England: Pearson Education.

Coxon, E., \& Munce, K. (2008). The global education agenda and the delivery of aid to Pacific education. Comparative Education, 44(2), 147-165.

Fullan, M. (2001). The new meaning of educational change (3rd ed.). New York, NY: Teachers College Press.

Huffer, E., \& Qalo, R. (2004). Have we been thinking upside-down? The contemporary emergence of Pacific theoretical thought. The Contemporary Pacific, 16(1), 87116.

OECD. (2005). Paris declaration on aid effectiveness. Paris, France: Author.

Pacific Islands Forum Secretariat. (2007). Pacific aid effectiveness principles. Koror, Palau: Author.

Robertson, J. (2005). Coaching leadership: Building educational leadership capacity through coaching partnerships. Wellington, New Zealand: NZCER Press. 
Strachan, J., \& Simi, J. (2010). Solomon Islands-School of Education Support Partnership (SISEP): Final quarterly report. Hamilton, New Zealand: Wilf Malcolm Institute of Educational Research.

Taylor, L., \& Pollard, B. (2004). School of Education review report and development plan. Solomon Islands: Solomon Islands College of Higher Education.

Wrightson, T. (2008). Review of the School of Education Partnership Link Programme (Evaluation Report Eva0829). Summary available from the New Zealand Aid Programme website: http://www.aid.govt.nz/what-we-do/review-and-evaluationreports.html

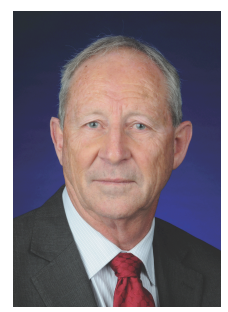

Clive McGee is a professor in the Wilf Malcolm Institute of Educational Research, University of Waikato. He was the foundation Director of the institute and before that Director of the Centre for Teacher Education. He has many years of teaching and research in curriculum, teaching and learning. He has directed numerous research projects involving teams from Waikato and other universities. The influential Professional Practice of Teaching (with Deborah Fraser) is among his many publications.

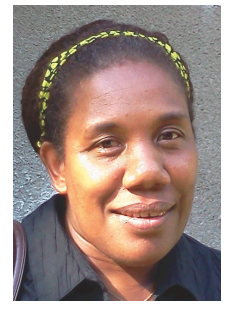

Patricia Rodie is currently Deputy Director at the Solomon Islands College of Higher Education (SICHE). She recently completed her doctoral thesis on beginning teachers' professional learning experiences in the Solomon Islands context at the University of Waikato. Her teaching and research interest include teachers' professional learning, curriculum planning, secondary teacher education, and educational leadership. She was involved in the initial planning, negotiations, and implementation of the Partnership in her capacity as the former Head of School of the School of Education, SICHE.

\footnotetext{
At the time of the Partnership NZAID was the name of New Zealand's aid programme. With a change in government there has been a restructuring and NZAID is now known as New Zealand Aid Programme.

ii InTREC played an important but minor role in the Partnership. After three years they ceased operation and were no longer involved.
} 
